\title{
OS PODERES DA CÂMARA ALTA NOS ESTADOS FEDERAIS
}

\section{THE POWERS OF THE UPPER HOUSE IN FEDERATIONS}

\author{
José Adércio Leite Sampaio \\ Pontifícia Universidade Católica de Minas Gerais - PUC/MG - (Belo Horizonte, MG, Brasil) \\ Escola Superior Dom Helder Câmara (Belo Horizonte, MG, Brasil)
}

Recebimento: 19 jul. 2017

Aceitação: 24 ago. 2017

\begin{abstract}
Como citar este artigo / How to cite this article (informe a data atual de acesso / inform the current date of access):
\end{abstract}

SAMPAIO, José Adércio Leite. Os poderes da câmara alta nos Estados federais. Revista da Faculdade de Direito UFPR, Curitiba, PR, Brasil, v. 63, n. 1, p. 41-63, abr. 2018. ISSN 2236-7284. Disponível em: <http://revistas.ufpr.br/direito/article/view/54021>. Acesso $\quad$ em: $\quad 30 \quad$ abr. $2018 . \quad$ DOI: http://dx.doi.org/10.5380/rfdufpr.v63i1.54021.

\section{RESUMO}

A câmara alta detém poderes de iniciar, emendar e aprovar projetos de lei que variam de um para outro Estado federal. Em alguns, esses poderes são iguais ou equiparáveis aos da câmara baixa. Noutros, atua apenas com o poder de veto suspensivo. Há, inclusive, a possibilidade de não participar do processo legislativo. A esses poderes, as constituições federais lhe acrescentam outros, como o de tribunal de impeachment, de dissolução do governo e de solução de questões federativas. Embora esses poderes formais não sejam definitivos para definir o papel e relevância institucionais da câmara, são, todavia, elementos que influenciam a prática política e constitucional. Para o estudo deste tema, adotou-se o método descritivo e analítico, buscando-se identificar semelhanças e, sobretudo, variedades de competências formalmente atribuídas pelos sistemas constitucionais às câmaras altas. Igualmente, realizou-se o estudo comparado como meio para compreensão do papel institucional da câmara alta federal.

PALAVRAS-CHAVE

Câmara Alta. Bicameralismo. Estado federal.

\begin{abstract}
The upper house holds powers to initiate, amend and approve bills that vary from one federal state to another. In some, these powers are equal or comparable to those of the lower house. In others, it acts with the power of suspensive veto only. There is also the possibility of not participating in the legislative process. There are other powers that federal constitutions add to the upper house, such as the court of impeachment, dissolution of government and solution of federal issues. Although these formal powers are not definitive in defining the institutional role and relevance of the house, they are nevertheless elements that influence political and constitutional practice. For the study of this theme, the descriptive and analytical method was adopted, seeking to identify similarities and, above all, varieties of competences formally attributed by the constitutional systems to the upper house. Likewise, the comparative study was performed as a way to understand the institutional role of the federal upper house.
\end{abstract}




\section{KEYWORDS}

Upper House. Bicameralism. Federal state.

\section{INTRODUÇÃO}

A Casa dos Lordes na Inglaterra é a matriz moderna das câmaras altas do Legislativo. Ela própria é uma evolução dos órgãos pluricamerais da Idade Média, compostos pelos vários status da sociedade feudal. Os reis a eles recorriam para discutir assuntos como a guerra e tributação (DREXHAGE, 2015, p. 7) ${ }^{1}$. Os convencionais da Filadélfia se basearam no modelo inglês, inspirados ainda no Senado romano, para instituírem seu próprio senado. Em vez dos lordes, a Casa Alta estadunidense passou a representar os Estados-membros da recém-criada Federação (BYRD, 1995; SWIFT, 2002, p. 9 et seq. $)^{2}$. Desde então passou a ser considerada um elemento central do federalismo (ALBERT, 2014, p. 957 et seq.; BRYCE, 1891, p. 173; CARRÉ DE MALBERG, 1948, p. 121-122).

A quase totalidade dos Estados federais a adotam, embora com diferenças mais ou menos marcantes (WATTS, 2015). Essas diferenças se podem referir à forma de composição, métodos de investidura, mandato e garantias de seus membros. Há, também, distinções relevantes nos poderes que a ela atribuem. A função precípua da câmara alta nas federações é dar voz às entidades subnacionais no processo legislativo federal. Há, todavia, atribuição de outras competências que podem estar diretamente relacionadas com a estrutura federativa ou serem a ela estranhas.

É a esse tema que o presente trabalho se dedica. O seu exame, seguindo o método descritivo e analítico, procura identificar as semelhanças e, sobretudo, variedades de competências que lhes são

\footnotetext{
${ }^{1}$ A existência de órgãos colegiados, compostos de sábios e virtuosos, em geral, de mais idade, destinados a assessorar os governantes, já era encontrada na Antiguidade. Nas cidades da Grécia antiga, o "Boulé” (ßou入ń) ou os "Boulai” eram conselhos compostos por cidadãos, nomeados para dirigir o dia a dia das cidades. No início, o rei os escolhia como consultores, tendo evoluído com o passar do tempo e o regime político das cidades. Nas aristocracias e oligarquias, os cargos eram hereditários. Nas democracias, os membros eram escolhidos por sorteio para servir, em regra, por um ano. Os mais famosos e conhecidos são os de Esparta ("Gerúsia”, conselho de anciãos com função legislativa - com a função principal de deliberar sobre medidas a serem submetidas à Casa Baixa, Ecclesia -, administrativa e judicial; e o "Eforado", conselho de líderes da antiga Esparta que compartilhava poder com o rei) e o de Atenas (o "Aerópago", que, na era préclássica, era integrado por pessoas mais velhas e sábias. Após as reformas de Efialtes e Péricles em meados do século V a. C., ficou apenas com a função de julgar homicídio. O "Boulé" assumiu suas funções administrativas e judiciais, supervisionando as finanças públicas, órgãos e servidores do Estado, e julgando os servidores por crimes funcionais). Eram compostos, inicialmente, por menos de cem membros, chegando a ter quinhentos, o que obrigou a duas subdivisões, que pode ter sido a inspiração do bicameralismo. Em Roma, havia a "Comitia Curiata", integrada pelas três tribos de Roma, para apoiar o novo rei, eleito pelo Senado, bem como dispor sobre o exército, e o Senado, originariamente, composto pelos anciãos, escolhidos pelo rei, para aconselhá-lo, tornando-se depois o órgão político mais importante até o surgimento do Império. Cf. HAMMOND, 1915, p. 38 et seq.; p. 57 et seq.; p. 169 et seq.; TSEBELIS; MONEY, 1997b, p. 17-18.

${ }^{2}$ Há quem veja, na criação do Senado, uma forma de garantir os privilégios das elites escravistas do Sul. Um Legislativo monocameral possibilitaria que os estados do Norte, mais populosos, pudessem dominar o processo decisório, pondo fim, inclusive, à escravidão (NEIVA; SOARES, 2013, p. 111; SCHUBERT; DYE; ZEIGLER, 2012, p. 32-33). A cópia da Casa dos Lordes, sem lordes, daria lugar à elite agrária estadual (SWIFT, 2002, p. 8 et seq.; WOOD, 1969, p. 57, 153).
} 
formalmente atribuídas pelos sistemas constitucionais. O estudo comparado fornece informações que são úteis e, por vezes, indispensáveis à compreensão do papel institucional da câmara alta federal.

\section{PARTICIPAÇÃO DA CÂMARA ALTA NO PROCESSO LEGISLATIVO FEDERAL}

A influência da casa alta no processo de formação das leis federais decorre de uma série de fatores. Em geral, no presidencialismo costuma ser maior do que no parlamentarismo. Principalmente nos Estados que adotam esse derradeiro sistema, a disciplina partidária e os poderes formais atribuídos à deliberação da casa podem conferir-lhe uma força diferencial. Do ponto de vista formal, pode haver um bicameralismo simétrico, integral ou completo, ou bicameralismo imperfeito, assimétrico ou incompleto. Diz-se completo ou simétrico quando há iguais poderes legislativos entre as duas casas, gerando, como consequência, a possibilidade de veto absoluto, por uma casa, ao projeto de lei aprovado na outra ${ }^{3}$. É como sucede, por exemplo, na Argentina (art. 78) ${ }^{4}$, na BósniaHerzegovina (art. 4(3)(c)), no Brasil, no Canadá (sec. IV(55)) e na Suíça (art. 156); ou assimétrico ou incompleto, quando ocorre o predomínio da casa baixa, detendo a casa alta, na maior parte das vezes, somente o poder de veto suspensivo, como sucede na maioria dos Estados federais. Pode haver, ainda, a distinção entre o bicameralismo obrigatório, quando todos ou, conforme o caso, alguns projetos de lei devem transitar pelas duas casas legislativas, e bicameralismo opcional ou facultativo, quando a intervenção da câmara alta não é condição necessária para a perfeição do processo, embora ela possa solicitar o exame ou apresentar objeções ${ }^{5}$.

Em regra, o bicameralismo opcional é também assimétrico, mas o obrigatório pode estar presente no bicameralismo incompleto. À câmara alta, o bicameralismo assimétrico pode prever intervenção obrigatória, facultativa e, até mesmo, hipóteses em que ela não ocorre. Como toda classificação, os binômios simétrico/assimético e obrigatório/facultativo devem ser compreendidos com as cautelas que a realidade e a política exigem ${ }^{6}$.

Entre a simetria e a assimetria, há gradações importantes. As casas legislativas costumam ter

\footnotetext{
${ }^{3}$ A literatura costuma ainda definir como "bicameralismo perfeito" aquele que envolve não somente o mesmo poder legislativo, mas também a possibilidade de as duas casas dissolverem o governo (CALABRÒ; COCCHIARA, 2015; DARDANELLI, 2005, p. 124; WÄLTI, 2001, p. 101).

${ }^{4}$ Sempre que for mencionado no texto, o artigo se refere à constituição em vigor e que consta das referências bibliográficas.

${ }^{5}$ Há distinção entre bicameralismo congruente e bicameralismo incongruente, que se refere à igualdade ou diferença da base de representação política das duas casas, gerando uma igual ou superior representação das minorias da câmara alta. Essa classificação, aliada à da simetria e assimetria, remete à definição de bicameralismo forte, mediano e fraco. Os sistemas mais fortes apresentariam poderes e legitimações equivalentes entre as casas (simetria) e maior representação das minorias na câmara alta (incongruência). Cf. LIJPHART, 1999.

${ }^{6}$ Há quem defenda que a simetria é condição necessária do bicameralismo. Cf. RIKER, 1992; ROGERS, 2001.
} 
competências exclusivas que podem diferençar seus papéis e pesos institucionais, ainda que possuam os mesmos poderes no processo legislativo, como, de regra, é o critério definidor dos dois extremos ${ }^{7}$. Não raras vezes, nuances institucionais, que variam de um para outro Estado federal, resultam, na prática, em maior ou menor prevalência da casa baixa no processo de formação das leis, ainda que, formalmente, haja similitude de poder entre elas. No Brasil, há igualdade formal entre as duas câmaras, mas como a casa iniciadora, que na grande maioria dos casos é a Câmara dos Deputados, pode desconsiderar alterações feitas pela casa revisora no projeto de lei e enviá-lo diretamente para sanção presidencial, aquela acaba tendo predominância do processo legislativo, exceto no caso de emenda constitucional (SAMPAIO, 2002, p. 508-509; VICENTE, 2012).

No Canadá, existe o poder formal de veto absoluto, que é raramente exercido, em virtude da falta de legitimidade do Senado (CAMERON, 2002, p. 111-112) ${ }^{8}$. O exame apenas do texto constitucional pode levar a conclusões apressadas, mas é um bom ponto de partida para o estudo comparado. A atribuição do poder de veto absoluto ao Bundesrat (ou Conselho Federal) alemão em relação a um rol relativamente grande de matérias dá-lhe um protagonismo maior do que os de seus pares noutros Estados parlamentaristas, notadamente na Áustria, ainda que, em ambos, o papel dos partidos políticos seja relevante (WATTS, 1996, p. 88).

As distinções formais se podem resumir a algumas iniciativas de projetos de lei, de modo a não afetar sensivelmente a simetria das duas $\operatorname{casas}^{9}$. Na Argentina, por exemplo, a iniciativa reservada à Câmara de Deputados para projetos de lei sobre contribuições e recrutamento de tropas (arts. 52 e 77). No Brasil, a Câmara dos Deputados é a casa iniciadora dos projetos de lei apresentados pelo presidente da República, Supremo Tribunal Federal e tribunais superiores (art. 64). No México, os projetos de lei que tratam de empréstimos, contribuições ou impostos e recrutamento de tropas devem ter sua discussão iniciada na Câmara dos Deputados (art. 72(H)). Nos Estados Unidos, a tramitação

\footnotetext{
${ }^{7}$ Alguns autores diferenciam cinco classes de assimetria. Totalmente simétricos: Estados Unidos, México, Nigéria e Suíça; simétricos com restrições: África do Sul, Argentina, Austrália, Índia, Malásia e Paquistão; competências exclusivas e veto: Alemanha e Brasil; assimétrico com poder de delongar o processo e função consultiva: Áustria e Canadá; assimétrico e subordinado à casa baixa: Rússia (PATTERSON; MUGHAN, 2001, p. 42 et seq.). Os próprios autores, no entanto, fazem mitigações sobre a classificação que adotam, ao lembrarem que o Senado dos Estados Unidos tem distinção quanto à iniciativa de projetos de lei tributária, restrita à Casa dos Representantes (PATTERSON; MUGHAN, 2001, p. 43).

${ }^{8}$ Como a maioria dos projetos de lei do Executivo se origina na Câmara dos Comuns, é costume haver gestões do governo para que o Senado decida o mais rapidamente possível, quando receber o projeto aprovado naquela Casa. Há procedimentos regimentais que preveem a remessa de estudos sobre o projeto de lei apresentado na Câmara a uma comissão permanente, de modo que, ao recebê-lo, o Senado estará em condições de rapidamente se manifestar a seu respeito. O Senado geralmente não faz muitas alterações nos projetos recebidos da Casa dos Comuns. Em geral, corrige erros de redação ou promove aperfeiçoamentos que tornem as leis mais exequíveis. As poucas modificações são, normalmente, acolhidas pela Câmara. Cf. CANADÁ, 2017.

${ }^{9}$ Se for tomado, rigorasamente, o bicameralismo perfeito como paridade absoluta entre as duas casas, só existiria o modelo imperfeito.
} 
de proposições que cuidam de aumento de receita pública inicia-se sempre pela Casa dos Representantes (art. 1(7)).

Na maioria dos Estados federais, as constituições estabelecem diferenças importantes de poderes entre as duas casas; normalmente, reduzindo o papel da casa alta. A iniciativa de projetos de lei é um desses pontos de distinção. As leis de natureza tributária ou de finanças públicas (empréstimos, garantias e fundos públicos) têm início invariavelmente na casa baixa na Austrália (sec. 53), no Canadá (sec. 4(53), na Índia (secs. 109) e no Paquistão (art. 73(2)). Nesses casos, a tendência é de a casa alta fazer recomendações que podem ou não ser acatadas pela casa baixa, como expressamente prevê a Constituição da Austrália (sec. 53), da Índia (Sec. 109(2)) e do Paquistão (art. 73(1) e (1A)). No Canadá, o poder de emenda senatorial é limitado. Na Áustria e na Bélgica, esses projetos nem sequer passam pela câmara alta (DREXHAGE, 2015, p. 28).

Na Alemanha, o Bundesrat não funciona como casa iniciadora, mas pode apresentar diretamente ao Bundestag (ou Parlamento Federal) projetos de lei, tendo de fazê-lo por intermédio do Governo Federal, que o envia juntamente com um parecer sobre o assunto (art. 76(1)). Em compensação, os projetos do Governo Federal devem ser também submetidos previamente ao Bundesrat para apreciação e emissão de parecer num prazo que varia de seis a nove semanas, conforme a complexidade do projeto ou caso se trate de reforma constitucional e de transferência de direitos de soberania (art. 76(2)). Na Áustria, o Bundesrat também não é a casa iniciadora do processo legislativo, mas pode encaminhar seus projetos de lei ao Nationalrat, o Parlamento Federal, com base na assinatura de um terço de seus membros ou por deliberação da maioria dos conselheiros (art. 41(1)) (ÁUSTRIA, 2017).

A intervenção do Bundesrat alemão pode ser obrigatória ou facultativa, hipóteses em que apresentará veto absoluto e supensivo ou relativo, respectivamente ${ }^{10}$. Na Áustria, a intervenção é obrigatória ou dispensada. No primeiro caso, o veto pode ser absoluto ou relativo. No caso alemão, na hipótese em que não é obrigatória a intervenção do Conselho, ele, ainda assim, pode apresentar objeção ao projeto aprovado na Casa Baixa, submetendo, primeiramente, a matéria à análise da Comissão de Mediação. A solução da Comissão (de emendar ou não o projeto) é enviada ao Conselho, que pode manter a objeção. Se ela for aprovada por maioria dos votos do Conselho Federal, poderá ser rejeitada por decisão da maioria dos membros do Parlamento Federal. Se o Conselho Federal tiver aprovado a objeção com uma maioria de pelo menos dois terços dos seus votos, a rejeição pelo

\footnotetext{
${ }^{10}$ Conforme sigam um ou outro rito, as leis são chamadas “Leis objetadas” (Einspruchsgesetze), no caso do bicameralismo facultativo, e "Leis consentidas” (Zustimmungsgesetze). Cf. LEHNERT; LINHART; SHIKANO, 2008.
} 
Parlamento Federal requer uma maioria de dois terços com um quórum que componha, pelo menos, a maioria dos membros do Parlamento Federal (art. 77(4)). Ocorre também a aprovação por decurso de prazo ou aquiescência tácita, se o Bundesrat alemão não se manifestar entre três e seis semanas, de acordo com a matéria, sobre projeto recebido da Câmara Baixa.

Há casos, porém, em que o Bundesrat tem intervenção obrigatória, detendo veto absoluto às leis oriundas do Parlamento. O projeto recebido daquela Casa pode ser aprovado, rejeitado ou submetido à Comissão de Mediação, retornando depois ao Conselho que pode aprovar a solução alvitrada ou arquivá-lo. O Bundesrat atua em pé de igualdade com o Bundestag sempre que se tratar de lei: (a) sobre matéria que recaia no âmbito da competência concorrente a ser executada pelo Land (estado) e que não lhe seja possível aprovar lei divergente (art. 84(1)); (b) que lhe imponha prestação de serviço às próprias expensas (art. 104(4)); (c) tributária, cuja arrecadação tenha de ser compartilhada com os Länder (estados; plural de Land) e municipalidades (art. 105(3)) e, enfim, (d) emenda à Constituição (art. 79(2)). Nessas hipóteses, deve manifestar sua objeção em "prazo razoável” (art. 77(2a) $)^{11}$. Como o país adota o federalismo executivo, quase a metade de toda legislação federal acaba passando pelo Bundesrat (HRBEK, 2002, p. 153; HUEGLIN; FENNA, 2015, p. 222).

Na Áustria, o Bundesrat não intervém nos processos legislativos referentes ao procedimento do Nationalrat, do orçamento federal e de determinadas leis financeiras. Tampouco pode fazer emendas ao projeto aprovado pelo Parlamento Federal. Na maioria dos casos, pode fazer objeção ao projeto, que pode ser derrubada pela maioria dos membros da Câmara Baixa. O Bundesrat tem oito semanas para objetar, sob pena de aprovação tácita (art. 42(4)). No caso de revisão total ou de emendas à Constituição que restrinjam competências dos Länder (art. 44(2) e (3)) e sobre decisão do presidente federal para dissolução de um parlamento estadual, é necessária a aprovação de dois terços dos membros do Bundesrat (art. 100) (ÁUSTRIA, 2017).

O poder de veto absoluto recebe muitas críticas, porém. Em geral, elas apontam, sobretudo na Alemanha, para o efeito paralisante das reformas, quando os partidos de oposição no Bundestag conseguem maioria no Bundesrat. Como esse não pode ser dissolvido, ao contrário daquele, a oposição pode bloquear os projetos legislativos e, em maior ou menor grau, os programas do Governo Federal. Mesmo que isso não ocorra, o Bundesrat obriga o Governo Federal a se articular com os governos estaduais para evitar problemas no processo legislativo. É de se observar ainda que, além

\footnotetext{
${ }^{11} \mathrm{O}$ presidente federal pode promulgar uma lei, mesmo em dúvida sobre a natureza de intervenção do Bundesrat. A palavra definitiva caberá ao Tribunal Constitucional Federal (ALEMANHA, 2017).
} 
do poder de bloqueio, os Länder podem, por meio de seus representantes, apresentar projetos de lei que atendam a seus interesses; o que não é um poder desprezível, pois os representantes são, em geral, políticos experientes e com liderança sobre os partidos (HUEGLIN; FENNA, 2015, p. 222-223).

Esse mecanismo de "checks and balances" tem permitido interpretações divergentes dos estudiosos. Há quem veja, na atividade do Bundesrat, um ingrediente confederado dentro da estrutura predominantemente federal do Estado alemão (WATTS, 2015, p. 13). Outros, no entanto, afirmam que os poderes do Conselho não têm evitado que o Estado federal alemão seja centralizado, ou quase um “federalismo unitário” (BENZ, 2009, p. 2). A conciliação é uma só: formalmente, é um traço confederado; na prática, um Estado federal centralizado. A razão seria até certo ponto paradoxal: como os Länder têm uma participação nos processos decisórios nacionais, diminuem as resistências à execução da legislação federal (HUEGLIN; FENNA, 2015, p. 225).

Na Bélgica, há três ritos previstos: o do bicameralismo obrigatório, o do bicameralismo opcional e o do monocameralismo. No primeiro, há a paridade de poder entre as duas Casas. A tramitação pode ser iniciada em uma ou outra e, havendo impasse entre elas, pode-se seguir em idas e vindas indefinidas. Dá-se assim em relação à revisão constitucional, a leis sobre os limites das quatro Regiões linguísticas, àquelas relacionadas à Comunidade germanofônica e seu financiamento, ao financiamento dos partidos e controle de despesas eleitorais, bem como as relativas à organização do Senado e ao status de senador (art. 77). No segundo rito, do bicameralismo opcional, o Senado tem quinze dias para decidir se irá examinar a matéria (droit d'évoque), havendo de se manifestar nesse sentido, pelo menos, trinta e um senadores e um terço dos membros de cada grupo linguístico (art. 78).

O Senado dispõe de trintas dias para examinar o projeto evocado, sob pena de aprovação tácita. Esse prazo pode ser ampliado se houver deliberação, nesse sentido, por uma comissão parlamentar de mediação (art. 82) ${ }^{12}$. Caso o Senado faça alguma emenda, o projeto retorna à Câmara, que decidirá a respeito. Esse é o procedimento para execução de leis com maioria especial, estrutura e funcionamento do Estado, organização e jurisdição do Conselho de Estado e garantia de obrigações internacionais ou supranacionais (art. 78, § 1). Nos projetos sobre assuntos que não estejam listados numa ou noutra hipótese, o procedimento é monocameral. É o caso, entre outras, das leis orçamentárias e financeiras, bem como sobre responsabilidade civil e criminal dos ministros de Estado, naturalização e o estabelecimento do contingente do exército (art. 74). As sucessivas reformas constitucionais, desde 1993, retiraram poder do Senado belga. A última, converteu-o numa casa "não

\footnotetext{
${ }^{12}$ Essa comissão também resolve disputas sobre o rito a ser seguido (art. 82).
} 
permanente” (art. 44(2)) (VERDUSSEN, 2015, p. 82).

Na África do Sul, o Conselho Nacional das Províncias tem iniciativa para propor leis relativas a matérias submetidas à concorrência legislativa entre União e províncias (sec. 68(2)). Detém, além do mais, poder de veto absoluto em relação a emendas constitucionais que tratem dos valores básicos da Constituição ou da declaração de direitos, que afetem o próprio Conselho ou que alterem os limites, os poderes, as funções ou as instituições de uma província (sec. 74), bem como aos projetos de lei ordinária que afetem os interesses provinciais, desde que se tenham iniciado no Conselho, sem que a comissão de mediação tenha chegado a um acordo (sec. 76). Terá, por outro lado, veto suspensivo, quando estiverem em causa os projetos de lei ordinária que não afetem interesses das províncias ou, se afetarem, tenham iniciado a tramitação na Assembleia Nacional, sem ter havido acordo na comissão de mediação dentro de trinta dias, desde que sejam, na sequência, aprovados pela maioria de dois terços da Assembleia. Também ele terá deliberação superável pela Assembleia nos casos de projetos de leis financeiras (sec. 77).

Na Malásia, o Senado tem um poder muito inferior ao da Casa dos Representantes. A iniciativa de leis financeiras e monetárias, por exemplo, não pode ocorrer no Senado (sec. 67(1)). E as emendas que possa fazer a projetos aprovados por aquela Casa - ou mesmo a sua rejeição - podem ser desconsideradas (sec. 68(2)). A exceção fica por conta de emendas à Constituição (secs. 68(5) e 159). São obrigatoriamente submetidos à consideração do Conselho da Federação Russa as propostas de emenda à Constituição (art. 108) e projetos de leis sobre orçamento federal, tributos federais, direito financeiro, moeda, crédito, regulação aduaneira e emissão de dinheiro, ratificação e denúncia de tratados e acordos internacionais, status e a proteção da fronteira estatal da Federação da Rússia e sobre guerra e paz (art. 106). Se o Conselho não deliberar em catorze dias, tem-se por aprovada a proposição (art. 105(4)). Objeções que venha a fazer podem ser superadas pelo voto da maioria de dois terços dos deputados (art. 105(5)), exceto no caso de emendas constitucionais (art. 108).

No Sudão e no Sudão do Sul, a intervenção do Conselho de Estados no processo legislativo apenas se dá quando os interesses dos estados forem afetados, conforme reconhecer uma comissão mista, formada por representantes da Assembleia e do próprio Conselho. O texto constitucional é dúbio sobre o poder de veto. Apenas reconhece que se o Conselho aprovar o projeto oriundo da Assembleia ou emendá-lo com o voto da maioria de dois terços dos representantes, ele seguirá para assinatura do presidente (arts. 91.5(c) e 60(c)). No Sudão, o Conselho tem, todavia, iniciativa de projetos de leis destinadas a proteger minorias religiosas contra normas jurídicas, cuja fonte seja outra religião ou costumes (art. 91.4(d)). E, no Sudão do Sul, para propor e aprovar aquelas destinadas à promoção de uma cultura de paz, reconciliação e harmonia entre todos os povos dos estados (art. 59 
(f)).

Na Bósnia-Herzegovina, o processo se inicia na Casa dos Representantes, podendo ser vetado pelo Conselho dos Povos, abrindo-se procedimento de mediação. Logo no começo dos trabalhos, na verdade, há um debate no colégio de representantes das duas Casas, como forma de evitar conflitos (GAVRIC; BANOVIC; BARREIRO, 2013, p. 66-67). Há, ainda, a possibilidade de bloqueio do processo legislativo bósnio, por manifestação dos delegados bósnios, croatas ou sérvios do referido Conselho, por veicular assunto que seja “destruidor de um interesse vital” de um desses grupos étnicos (art. IV(3)(e)). Na Etiópia, a Casa da Federação não participa do processo legislativo ordinário, mas tem intervenção obrigatória na emenda à Constituição. Dois terços de seus membros, concorrentemente com dois terços dos deputados da Casa dos Representantes e com um terço das assembleias estaduais, podem apresentar proposta de emenda (art. 104). A aprovação depende do voto de dois terços dos membros da Casa da Federação e da Casa dos Representantes, em sessão conjunta com o referendo de dois terços das assembleias estaduais (art. 105(2)). No caso de emenda que afete direitos e liberdades, é preciso que haja apoio de, pelo menos, dois terços dos deputados e de membros da Casa da Federação, em votação separada, além da aprovação de todas as assembleias estaduais, por maioria de seus membros (art. 105(1)).

Resumidamente, os poderes da casa alta dos Estados federais contemplam:

- $\quad$ Veto absoluto: Argentina (art. 77), Bósnia-Herzegovina (art. 4(3)(c)), Canadá (sec. IV(55)), Estados Unidos (art. 1(7)), Etiópia, no caso de emenda constitucional (art. 105(1)) e Suíça (art. 156).

- Veto suspensivo: aparentemente, é a interpretação que se extrai do texto constitucional do Sudão (art. 91.5(c) e do Sudão do Sul (at. 60(c)).

- $\quad$ Veto absoluto ou suspensivo: África do Sul (secs. 74, 75 e 77), Alemanha (arts. 77 e 84), Áustria (arts. 42(4) e 44(2)), Bélgica (arts. 77 e 78), Brasil (art. 65, caput e parágrafo único), Índia (secs. 109, 110 e 117), Malásia (secs. 67 e 68), Paquistão (sec. 73) e Rússia (arts. 105, 108, 136).

Os mecanismos de solução do impasse entre as duas casas legislativas são relevantes, não apenas para adoção dos projetos de governo, mas para a sua própria estabilidade, especialmente nos sistemas parlamentaristas (HUEGLIN; FENNA, 2015, p. 223). A solução canadense foi evitá-lo, por meio de um senado cujos membros são indicados pelo governo federal. Um senado quase mudo. Quando se opta por uma casa alta com algum protagonismo, o conflito é mais que previsível, embora possa não ocorrer. Há três mecanismos de solução: “navette” (“shuttle”), instituição de uma comissão 
mista de mediação ou convocação de sessão conjunta ${ }^{13}$. A primeira impõe sucessivas idas e vindas dos textos entre as Casas até que haja consenso ou arquivamento. Na Bélgica, nos casos do bicameralismo obrigatório e, no Brasil, em relação às propostas de emenda constitucional (art. 65, parágrafo único), por exemplo.

A solução mais usual é a criação de comissão de conferência ou mediação. As fórmulas de sua instituição são variadas, de acordo com: a) quem pode criá-la; b) quem a compõe; c) a sua duração (se ad hoc ou permanente); (d) os poderes que possui; (e) os procedimentos decisórios; (f) a eficácia de suas deliberações e (g) quem detém a palavra final (TSEBELIS; MONEY, 1997, p. 178-179). Nos Estados Unidos, há a previsão legal e regimental da “congressional conference committee”, instituída ad hoc com a finalidade de conciliar as diferenças existentes entre a Casa dos Representantes e o Senado acerca de um determinado projeto de lei. Essa comissão é integrada, normalmente, por membros seniores das comissões permanentes de cada Casa que discutiram a proposição (SHEPSLE; WEINGAST, 1987).

Quando um projeto de lei recebe alterações significativas na casa revisora, é feita uma comunicação à casa iniciadora. Se discordar, ela pode solicitar a instalação de uma conferência, indicando os nomes que a representarão e dando ciência à outra casa. Se a casa mantiver as alterações e concordar com a conferência, nomeia seus representantes. O número de conferencistas não precisa ser igual para as duas, mas é preciso que, para que se obtenha um acordo, a maioria da delegação de cada uma delas vote no mesmo sentido (TSEBELIS; MONEY, 1997, p. 163). É comum que os conferencistas se limitem às matérias que lhes são afetas, mas pode ocorrer de introduzirem assuntos novos. O projeto de lei aprovado pela comissão segue para as duas Casas, não podendo ser alterado. Nada impede, porém, que um parlamentar da primeira Casa, ao concluir o exame do relatório da conferência, submeta outra vez o projeto para reexame da comissão. Se, por outro lado, houver aprovação do projeto, a comissão é dissolvida, cabendo à segunda Casa aquiescer com a matéria ou rejeitá-la (LONGLEY; OLESZEK, 1989; MCQUILLAN; ORTEGA, 1992).

Na Alemanha, procurou-se uma alternativa, inspirada nas comissões de conferências estadunidenses, por meio de uma comissão conjunta e paritária de membros do Bundestag e dos Bundesrat - a comissão de mediação (art. 77). À diferença de seu par norte-americano, que é instituído ad hoc, a comissão de mediação é um órgão permanente (HUEGLIN; FENNA, 2015, p. 223). Sua convocação se pode dar pelo Conselho Federal diante de discordância do projeto aprovado

\footnotetext{
${ }^{13}$ Na Austrália, há uma quarta via: submissão ao eleitorado. Essa “arbitragem popular” apenas ocorre em proposta de emenda à Constituição (sec. 128).
} 
pelo Parlamento Federal (art. 77(2)). Se, dessa comissão, houver sugestão de emenda ao texto da lei, o Parlamento a realizará, submetendo o novo texto ao Bundesrat, que, ainda assim, poderá apresentar objeção. O prazo para apresentá-la é de duas semanas, contado do recebimento da comunicação do presidente da comissão ou, no caso de alteração do texto da lei, do recebimento da nova resolução do Parlamento (art. 77(3)). Em geral, porém, a comissão é um poderoso meio de resolução de conflitos, havendo um compromisso de acolher suas deliberações (HUEGLIN; FENNA, 2015, p. 223).

Na Suíça, havendo o impasse entre deliberações discordantes das duas casas legislativas, elas tentam encontrar uma solução de compromisso, por meio de um procedimento que envolve negociação entre seus delegados numa comissão de mediação. Na ausência de acordo, o projeto é arquivado (art. 156(3)). Na Bélgica, também há a previsão de uma comissão parlamentar de concertação, composta paritariamente (art. 82). No Canadá, há previsão no regimento da Casa dos Comuns e do Senado de uma “comissão conjunta”, que não é convocada desde 1947 (HAYS, 2008, p. 8; TSEBELIS; MONEY, 1997, p. 162-163).

Na África do Sul, também há uma comissão de mediação, instituída para resolução de conflitos entre as duas casas legislativas nos processos em que a intervenção do Conselho Nacional das Províncias é obrigatória (sec. 78). A ineficácia de sua intervenção pode resultar no arquivamento do projeto, se ele tiver início do Conselho Nacional, ou haver predominância da vontade da Assembleia Nacional pelo voto de dois terços de seus membros. Uma alternativa para contornar o arquivamento seria reintroduzir a mesma matéria pela Assembleia (WHITTLE, 2016, p. 32). Assim também se, na Rússia, o Conselho vetar uma lei aprovada pela Duma, a Câmara Baixa - instala-se um comitê de conciliação para elaborar um texto de compromisso, que tornará a ser votado pelas duas câmaras. Entretanto, o veto do Conselho da Federação pode ser superado pela maioria de dois terços na Duma (art. 105.4 e 5).

Na Índia, o presidente pode convocar uma sessão conjunta das duas casas. O impasse pode ser resolvido por maioria simples (sec. 108), exceto para as leis financeiras, cujas recomendações do Conselho dos Estados podem ser desconsideradas pela Casa do Povo (sec. 109.4). Há, todavia, um instrumento destinado a prevenir impasse: a possibilidade de constituição de uma comissão mista que procura, por meio de audiências públicas e acordos políticos, obter um texto consensual. Esse texto não vincula as Casas, mas tende a ser acatado (SHARMA, 2015, p. 188; SINGHVI, 1970). A casa iniciadora, no Paquistão, pode pedir uma sessão conjunta para resolver o impasse. Havendo concordância da maioria de seus membros, o projeto é aprovado (art. 70(3)). Pode haver prévia dissolução das Casas e, com a nova legislatura, haver a deliberação conjunta se permanecer o impasse, como sucede na Austrália (sec. 57). Como o número de membros da Casa Alta é menor do que o da 
Casa Baixa, a alternativa de deliberação conjunta acaba por dar predominância a essa última sobre a primeira, na prática.

Na Bósnia-Herzegovina, a solução do impasse transita por mais instituições. Se houver uma simples discordância entre os textos aprovados pelas duas Casas, é instituída uma comissão conjunta e paritária para tentar harmonizar os textos (GAVRIC; BANOVIC; BARREIRO, 2013, p. 67). Há, porém, um incidente mais grave: bloqueio do processo legislativo, por manifestação dos delegados bósnios, croatas ou sérvios do Conselho dos Povos, quando se trata de assunto que seja “destruidor de um interesse vital” de um desses grupos étnicos. Se a maioria dos delegados bósnios, croatas ou sérvios se opuser ao bloqueio, o Presidente da Câmara dos Povos convocará imediatamente uma comissão mista composta por três delegados, um bósnio, um croata e outro sérvio, para resolver a questão. Se a Comissão não o fizer no prazo de cinco dias, a questão é submetida ao Tribunal Constitucional (art. IV(3)(f)). Um incidente semelhante se pode dar no âmbito da Presidência, que é formada por um membro eleito de cada grupo étnico, contra decisão tomada por aquele órgão. O assunto será levado à deliberação dos delegados bósnios ou dos delegados croatas na Casa dos Povos, conforme tenha sido suscitada pelo presidente bósnio ou pelo presidente croata. Caso seja suscitada pelo presidente sérvio, o assunto é levado à Assembleia Nacional da República Srpska (Sérvia). Se o incidente for confirmado por dois terços dos votos dessas pessoas no prazo de dez dias, a decisão é anulada (art. $\mathrm{V}(2)(\mathrm{d}))$.

Em breve exame, sob aspecto da atribuição constitucional de competências, pode-se notar uma simetria exemplar na Suíça, em primeiro nível, seguida, num segundo patamar, pela Argentina, Brasil e Estados Unidos, e, mais abaixo, pela Alemanha e pela Bélgica, pelo Canadá e pela Índia. Logo abaixo, pela Rússia, enquanto a Áustria é um dos Estados mais assimétricos (SWEDEN, 2004, p. 36).

Uma relação pode ser estabelecida entre a forma de investidura dos membros da casa alta e dos seus poderes legislativos. Em regra, a eleição direta está acompanhada de maiores poderes, enquanto a eleição indireta é a preferida para as casas que detêm menos poderes legislativos (COAKLE; LAVER, 1997, p. 50-52).

\section{QUESTÕES FEDERAIS}

A casa alta é, na maioria dos estados federais, um espaço de garantia da autonomia subnacional, de solução de conflitos federativos e de deliberação de uma série de assuntos relacionados à federação. Na África do Sul, cabe-lhe a aprovação e supervisão da intervenção 
provincial nos municípios (sec. 139) e a intervenção nacional nas províncias (sec. 100). Na Áustria, os tratados firmados pelos Länder requerem aprovação do Bundesrat, caso se trate de matérias relacionadas à esfera autônoma de competências estaduais (art. 50(2)(2)). No Brasil, o Senado desempenha papel importante no controle das finanças públicas. Cabe-lhe autorizar operações externas de natureza financeira, de interesse da União, dos estados, do Distrito Federal, dos territórios e dos municípios, e dispor sobre limites e condições para: (i) o montante da dívida consolidada e para as operações de crédito externo dos três níveis da Federação, incluindo o Distrito Federal; (ii) o total da dívida mobiliária dos estados, do Distrito Federal e dos municípios; (iii) a concessão de garantia da União em operações de crédito externo e interno (art. 52, V a IX). Detém ainda competências privativas importantes no campo tributário com vistas a reduzir a guerra fiscal entre estadosmembros, fixando limites ao ICMS. É ele que, por iniciativa do presidente da República ou de um terço dos senadores, aprovada pela maioria absoluta de seus membros, estabelece as alíquotas aplicáveis às operações e prestações, interestaduais e de exportação. Pode, ainda, fixar alíquotas mínimas nas operações internas, mediante resolução de iniciativa de um terço e aprovada pela maioria absoluta de seus membros, e alíquotas máximas nas mesmas operações para resolver conflito específico que envolva interesse de estados, mediante resolução de iniciativa da maioria absoluta e aprovada por dois terços de seus membros (art. 155, IV e V (a) e (b)).

No México, compete-lhe a nomeação de governador provisório de entidade federativa cujos poderes constitucionais tenham desaparecido, a partir de lista tríplice enviada pelo presidente (art. 76, V), a resolução de questões políticas que surjam entre os poderes de uma entidade federativa, quando algum deles recorre ao Senado ou quando, em razão de tais questões, tenha sido interrompida a ordem constitucional, mediando um conflito de armas (art. 76, V), bem como a autorização dos convênios que as entidades federativas celebrem sobre seus respectivos limites (art. 76, X).

Na Rússia, é de competência da Casa Alta a aprovação de mudanças nas fronteiras entre os sujeitos federativos (art. 102.1). No Sudão e Sudão do Sul, cabe-lhe aprovar resoluções e diretrizes que possam orientar todos os níveis de governo sobre política de descentralização e relações intergovernamentais (arts. 91.4(b); 59(b)) e solicitar aos ministros nacionais informações sobre o sistema descentralizado e de delegação de poderes (arts. 91.4(g) e 49(e)). No caso do Sudão, ainda compete ao Conselho decidir sobre as objeções dos estados contra deliberações da Comissão Nacional do Petróleo, submetendo-as, se aprovadas, à decisão arbitral (art. 191, 4(d)). No Sudão do Sul, estão afetos assuntos relacionados à reconstrução nacional, desenvolvimento e prestação de serviços equitativos pelos estados (art. 49(c)), e à aprovação de mudanças de nomes de estados, capitais e limites (art. 49(g)). 
Mesmo quando não há expressa previsão constitucional, a casa alta pode ser um espaço privilegiado de interlocução e de relação intergovernamentais. É o caso do Bundesrat alemão. Em virtude de em sua composição estarem presentes membros dos governos estaduais, a Casa funciona como um facilitador da cooperação e colaboração intergovernamental (BENZ, 2009, p. 4).

\section{O IMPEACHMENT E DISSOLUÇÃO DO GOVERNO}

A casa alta é, em muitos Estados federais, o tribunal de impeachment ou órgão de julgamento político dos cargos mais altos da federação. Nos Estados Unidos, compete ao Senado julgar “todos os processos de impeachment” (art. I(3)(6)). Na Argentina, é o Senado que julga o presidente, vicepresidente, chefe de gabinete de ministro, ministros e membros da Suprema Corte (art. 59). No Brasil, o Senado processa e julga ministros do Supremo Tribunal Federal, os membros do Conselho Nacional de Justiça e do Conselho Nacional do Ministério Público, o procurador-geral da República, o advogado-geral da União, o presidente e o vice-presidente da República nos crimes de responsabilidade, bem como os ministros de Estado e os comandantes da Marinha, do Exército e da Aeronáutica nos crimes da mesma natureza conexos com aqueles (art. 52, I e II). Na Rússia, julga o presidente da República (art. 102(1)(f)). No México, cabe ao Senado conhecer em juízo político as faltas dos senadores e deputados, do procurador-geral da República, dos ministros da Suprema Corte, dos conselheiros da Judicatura Federal, dos magistrados de circuito e juízes de distrito, e do Tribunal Eleitoral, dos conselheiros eleitorais e do secretário executivo do Instituto Nacional Eleitoral, dos integrantes dos órgãos constitucionais autônomos, dos diretores gerais e seus equivalentes dos organismos descentralizados, das empresas com participação estatal majoritária, sociedades e associações assimiladas e fideicomissos públicos (art. 76, VII). Como se nota, o presidente da República não se acha submetido a juízo de impeachment (CASAR, 1999; PULIDO, 2017).

Nos sistemas parlamentaristas, embora a maioria das câmaras altas possam ter o direito a requisitar informação do governo, fazer-lhe recomendações e criar comissões parlamentares que o fiscalize, cabe, geralmente, apenas à câmara baixa destituí-lo (RUSSEL, 2000, p. 193; TSEBELIS; MONEY, 1997, p. 1-2). Duas exceções existem. Na Suíça, nenhuma câmara pode fazê-lo (DREXHAGE, 2015, p. 25). Na Austrália, embora formalmente o Senado não possa emitir voto de desconfiança, ele chega ao mesmo objetivo, por meio da rejeição do projeto de lei orçamentária que lhe tenha sido enviado pelo primeiro-ministro, como sucedeu em 1974 e 1975 (RUSSELL, 2000, p. 203). 


\section{A PARTICIPAÇÃO NA FORMAÇÃO DO GOVERNO E NAS NOMEAÇÕES DE ALTOS DIGNATÁRIOS PÚBLICOS}

Nos sistemas parlamentaristas, a Câmara Alta não participa da formação do governo (TSEBELIS; MONEY, 1997, p. 1-2). A exceção fica, outra vez, por conta da Suíça. Os membros do governo suíço são nomeados pelas duas Câmaras conjuntamente (DREXHAGE, 2015, p. 25). Nos sistemas presidencialistas ou semipresidencialistas, notadamente a casa alta participa nos processos de nomeação de altos dignatários públicos.

Nos Estados Unidos, depende da aprovação do Senado a indicação presidencial para diversos cargos públicos como embaixadores, ministros e cônsules, juízes da Suprema Corte e todos aqueles que venham a ser previstos em lei (art. II(2)(2)). No Brasil, cabe ao Senado aprovar previamente, por voto secreto, após arguição em sessão secreta, a escolha dos chefes de missão diplomática de caráter permanente, e, após arguição pública, a escolha de membros do Supremo Tribunal Federal, do Superior Tribunal de Justiça e do Tribunal Superior do Trabalho, de ministros do Tribunal de Contas da União indicados pelo Presidente da República, governador de território, procurador-geral da República, membros do Conselho Nacional de Justiça e do Conselho Nacional do Ministério Público, presidente e diretores do banco central e titulares de outros cargos que a lei determinar (arts. 52, III (a) a (f) e IV; 103B, § $2^{\circ}$, e 130A).

No México, é o Senado quem nomeia os ministros da Suprema Corte de Justiça da Nação, dentre os integrantes de lista tríplice apresentada pelo presidente da República, assim como outorga ou nega aprovação a pedidos de licença ou renúncia dos ministros (art. 56, VIII). É ele que integra a lista de candidatos para a Procuradoria-Geral da República, nomeia o procurador-geral e faz objeção à sua remoção (art. 76, XIII), que ratifica as nomeações de alguns secretários de Estado, no caso de um governo de coalizão (art. 76, I), e nomeia comissionados da agência garantidora de informação pública (art. 76, XII). Na Rússia, cabe ao Conselho aprovar as indicações do presidente a membros do Tribunal Constitucional da Federação Russa, da Suprema Corte da Federação Russa e do Supremo Tribunal de Arbitragem do Governo Federal da Rússia, bem como a Procurador-Geral da Federação Russa e a outros dignatários da República (art. 102.1). No Sudão, o Conselho de Estado aprova a indicação dos juízes do Tribunal Constitucional (art. 91.4(c)).

\section{OUTRAS FUNÇÕES DA CASA ALTA}

Diversas outras funções não necessariamente ligadas à federação são atribuídas à casa alta. Na Áustria, o Bundesrat pode fiscalizar a administração do governo federal, interrogar seus membros 
sobre matérias relacionadas à execução, bem como requisitar-lhe informações (art. 52(1)). Compete formalmente ao Senado dos Estados Unidos consentir, pelo voto de dois terços de seus membros, que o presidente da República celebre tratados internacionais (art. II(2)(2)).

O Senado do México tem atribuições relacionadas à: (a) política exterior - analisa a política externa desenvolvida pelo Executivo federal. Além disso, aprova tratados e convenções internacionais, bem como sua denúncia, suspensão, alteração, revogação, reservas e faz declarações interpretativas a respeito de tais assuntos (art. 76, I). Além disso, cabe-lhe autorizar a saída de tropas nacionais do país e a passagem de tropas estrangeiras no território ou em águas nacionais (art. 76, III) e (b) segurança pública - é o Senado quem aprova a Estratégia Nacional de Segurança Pública no prazo previsto por lei (art. 76, XI) e quem dá o consentimento para o presidente da República ter a Guarda Nacional fora de seus respectivos estados, fixando a força necessária (art. 76, IV).

No Brasil, o Senado exerce diversas funções, além das enumeradas precedentemente, entre as quais: (a) suspender a execução, no todo ou em parte, de lei declarada inconstitucional por decisão definitiva do Supremo Tribunal Federal (art. 52, X); (b) eleger dois membros do Conselho da República (art. 52, XIV), indicar um nome para compor o Conselho Nacional de Justiça e um nome para o Conselho Nacional do Ministério Público (arts. 103B, XIII; 130A, VI) e (c) avaliar periodicamente a funcionalidade do Sistema Tributário Nacional, em sua estrutura e seus componentes, e o desempenho das administrações tributárias dos entes federativos (art. 52, XV).

Na Rússia, compete ao Conselho a aprovação do decreto do presidente da Federação da Rússia sobre a introdução da lei marcial e sobre a introdução do estado de emergência, sobre a possibilidade de utilizar as Forças Armadas da Federação Russa fora do território da Federação Russa, bem como a declaração de eleições do presidente da Federação Russa (art. 102.1). Na Argentina, é também o Senado que autoriza o presidente da Nação a declarar estado de sítio (art. 61). No Sudão, o Conselho de Estado supervisiona o Fundo Nacional de Reconstrução e Desenvolvimento (art. 91.4(e)). No Sudão do Sul, é da alçada do Conselho de Estados o monitoramento de repatriação, reassentamento, reabilitação e reinserção de pessoas deslocadas internamente, e a reconstrução de áreas afetadas por conflitos ou desastres (art. 59(c)).

\section{CONSIDERAÇÕES FINAIS}

A câmara alta federal tem a função precípua de integrar a vontade das unidades subnacionais no processo legislativo federal. Essa competência pode ser maior ou menor, de acordo com a solução adotada em cada Estado. Nalguns deles, ela pode estar praticamente em pé de igualdade com a câmara 
baixa, representativa do povo, detendo direito de iniciativa e de emenda no processo legislativo, além de poder arquivar proposição aprovada na outra câmara. Algumas matérias não podem iniciar, porém, na câmara alta. De regra, são propostas de orçamento (Argentina, Brasil), tributação (Estados Unidos) ou de finanças públicas em geral (Austrália, Canadá, Índia, México e Paquistão). Na Argentina, Bósnia-Herzegovina, Canadá, Estados Unidos, Etiópia (processo de emenda constitucional) e Suíça, a câmara alta tem poder de veto absoluto em relação a projetos de lei oriundos da outra câmara. O veto meramente suspensivo é, formalmente, encontrado no Sudão e no Sudão do Sul.

Noutros Estados, como a África do Sul, a Alemanha, a Áustria, a Bélgica, o Brasil, a Índia, a Malásia, o Paquistão e a Rússia, o veto da câmara alta pode ser absoluto ou suspensivo, de acordo com o objeto do processo legislativo ou da matéria em discussão. Em geral, é absoluto em relação a emendas constitucionais, mas pode ser relativo, nos demais processos legislativos, como no Brasil. Na Alemanha, por exemplo, é absoluto no caso de emenda à Constituição e de determinadas matérias enumeradas constitucionalmente. Na Áustria, é absoluto em relação a emenda constitucional que restrinja a competência estadual ou os poderes da Câmara Alta e relativo nos demais casos. Em ambas, Alemanha e Áustria, o Bundesrat não pode fazer emenda a projetos aprovados pela Câmara Baixa. As leis financeiras são fator diferencial na Índia e no Paquistão, tratando-se, nesse caso, de veto suspensivo, enquanto pode bloquear deliberação da Câmara Baixa noutros temas.

Há uma distinção importante entre os sistemas federais, de acordo com a obrigatoriedade, facultatividade e dispensa do bicameralismo. Nalguns, o bicameralismo é obrigatório sempre: Argentina, Brasil, Canadá, Estados Unidos, México. Noutros, há casos de bicameralismo obrigatório e casos de bicameralismo facultativo, como na Alemanha e na Bélgica. Ou, ainda, a dispensa de intervenção da câmara alta, como na própria Bélgica em relação aos temas que não se enquadrem nos dois casos anteriores, mas também na África do Sul, nas proposições que não alterem os limites, os poderes, as funções ou as instituições de uma província; na Áustria, em relação à lei orçamentária; no Sudão e no Sudão do Sul, quando os interesses dos estados não forem afetados, conforme reconhecer uma comissão mista, formada por representantes da Assembleia e do próprio Conselho.

Ocorre também a aprovação por decurso de prazo ou aquiescência tácita - se o Bundesrat não se manifestar entre três e seis semanas (na Alemanha) ou em oitos semanas (na Áustria) sobre projeto recebido da Câmara Baixa, ele é tido por aprovado (art. 42(4)). Se o Conselho malaio não deliberar em catorze dias, tem-se por aprovada a proposição (art. 105(4)). Na Bélgica, o Senado tem quinze dias para decidir se irá examinar projeto de lei, quando se trata de bicameralismo facultativo. Se, pelo menos, trinta e um senadores e um terço dos membros de cada grupo linguístico entenderem que o farão, passam a ter trintas dias para deliberar sobre o projeto evocado, sob pena de aprovação 
tácita.

O veto é situação-limite. Em diversos sistemas, há mecanismos para solução dos impasses entre as duas câmaras legislativas, como a instituição de uma comissão mista de mediação (África do Sul, Alemanha, Bósnia-Herzegovina, Canadá - embora não empregada há muito tempo -, Estados Unidos, Rússia e Suíça) ou convocação de sessão conjunta das duas câmaras (Austrália, após dissolução em virtude do impasse, Índia, Paquistão). Existe ainda um terceiro meio, que são as sucessivas idas e vindas dos textos entre as casas até que haja consenso ou arquivamento, chamado de "navette" ou "shuttle”. É o caso brasileiro, para as emendas constitucionais, e da Bélgica, nas hipóteses de bicameralismo obrigatório.

A câmara alta detém ainda competência para resolver diversas questões federativas, como a aprovação ou autorização de mudanças nas divisas entre os sujeitos federativos (México, Rússia), conflitos entre entidades federativas (México), tratados firmados pelos Länder (Áustria), convênios entre as entidades federativas (México), orientação sobre política de descentralização e relações intergovernamentais (Sudão e Sudão do Sul), intervenção federal e estadual (África do Sul), nomeação de governador provisório em estado sob intervenção (México).

É ela também o tribunal de impeachment ou órgão de julgamento político dos cargos mais altos da federação, incluindo o presidente da república (Argentina, Brasil, Estados Unidos e Rússia) ou excluindo-o (México). Nos sistemas parlamentaristas, embora o poder de destituir o governo esteja, de regra, somente com a câmara baixa, pode ocorrer de se chegar ao mesmo efeito, como ocorreu em 1974 e 1975, na Austrália, com a rejeição do projeto de orçamento enviado pelo governo.

A casa apresenta, ainda, um papel relevante também para aprovar indicações feitas pelo chefe do Executivo para altos cargos públicos, como membros do Tribunal Constitucional (Rússia e Sudão), da Suprema Corte (Estados Unidos, México) e procurador-geral da República (México).

Outras funções não necessariamente ligadas à federação são atribuídas à câmara alta, como a fiscalização do governo federal (Áustria, México), a aprovação de tratados e convenções internacionais (México), o uso das forças armadas (Argentina, México, Rússia), a decretação de estado de exceção (Rússia), controle da dívida pública (Brasil), suspensão de ato declarado inconstitucional pela suprema corte (Brasil) e acompanhamento da reconstrução nacional e política sobre pessoas deslocadas internamente (Sudão e Sudão do Sul).

Claro está que esses são elementos formais que se devem conjugar com aspectos culturais e políticos, notadamente a representação e atividade partidárias, para se ter ideia mais exata dos poderes efetivos da câmara alta. Seja como for, são, eles mesmos, relevantes tanto para influenciar a prática político-constitucional dos atores envolvidos, quanto para serem por ela influenciados. A comparação 
permite o exercício intelectual nos dois sentidos.

\section{REFERÊNCIAS}

ÁFRICA DO SUL. Constitution of 1996 (Atualizada em 2005). Disponível em: <https://goo.gl/3DGPEf>. Acesso em: 15 mar. 2017.

ALBERT, Richard. Constitutional amendment by constitutional desuetude. American Journal of Comparative Law, v. 62, n. 3, p. 641-686, 2014.

ALEMANHA. Bundesrat. Consent and Objection Bills, 2017. Disponível em: <https://goo.gl/FNFNM9>. Acesso em: 15 mar. 2017.

ALEMANHA. Lei Fundamental de Bonn. (Atualizada até janeiro 2011). Disponível em: <https://goo.gl/3YUBML>. Acesso em: 15 mar. 2017.

ARGENTINA. Constitución de 1853 (Atualizada em 15/12/1994). Disponível em: <https://goo.gl/WprusX>. Acesso em: 15 mar. 2017.

AUSTRÁLIA. Constituição de 1900 (com emendas até 1977). Disponível em: <https://goo.gl/g8Yj3N>. Acesso em: 15 fev. 2017.

ÁUSTRIA. Constitution of 1920, Reinstated in 1945, with Amendments through 2013. Disponível em: <https://goo.gl/aQMJBB>. Acesso em: 15 mar. 2017.

ÁUSTRIA. Parliament. Procedure in the Federal Council, 2017. Disponível em: <https://goo.gl/nHfTSn>. Acesso em: 11 mar. 2017.

BÉLGICA. Constitution of 1831 (Atualizada em 05/2014). Disponível em: <https://goo.gl/XUxZQm>. Acesso em: 15 mar. 2017.

BENZ, Arthur. Intergovernmental Relations in German Federalism - Joint Decision-Making and the Dynamics of Horizontal Cooperation. In: Seminario Internacional la Federalización em España: Los Déficit de la Cooperación Intergubernamental, p. 1-28, 2009. Disponível em: <https://goo.gl/A2ZfE4>. Acesso em: 11 ago. 2016.

BÓSNIA-HERZEGOVINA. Constitution of 1995 with Amendment through 2009. Disponível em: <https://goo.gl/gcFVpc>. Acesso em: 15 mar. 2017.

BRASIL. Constituição Federal de 1988 (Atualizada em 6/6/2017). Disponível em: <https://goo.gl/lM0x>. Acesso em: 9 jun. 2017.

BRYCE, James. Studies in History and Jurisprudence. V. 2. Oxford: Clarendon Press, 1891.

BYRD, Robert C. The Senate of the Roman Republic: Addresses on the History of Roman Constitutionalism. Washington, D.C.: Government Printing Office, 1995. 
CALABRÒ, Vittoria; COCCHIARA, M. Antonella. The form of parliamentary government and 'perfect' bicameralism in the Italian constitutional system: at the beginning of the Italian constituents' choices (1946-47). Parliaments, Estates and Representation, v. 35, n. 1, p. 84-108, 2015.

CAMERON, David R. Canada. In: GRIFFITHS, Ann L.; NERENBERG, Karl. (Ed.). Handbook of Federal Countries, 2002. Montreal; London; Ithaca: McGill-Queen's University Press, p. 106-115, 2002.

CANADÁ. Constituição de 1867 (com emenda de 1982). Disponível em: <https://goo.gl/Vj4Xah>. Acesso em: 15 fev. 2017.

CANADÁ. House of Representatives. Legislative Process, 2017. Disponível em: <https://goo.gl/prUaF3>. Acesso em: 15 mar. 2017.

CARRÉ DE MALBERG, R. Teoría General del Estado. Trad. José Lión Depetre. Mexico: Fondo de Cultura Económica, 1948 [1920].

CASAR, María Amparo. Las relaciones entre el poder ejecutivo y el legisltaivo: el caso de México. Política y gobierno, v. 6, n. 1, p. 83-128, 1999.

COAKLE, John; LAVER, Michael. Options for the Future of Seanad Eireann. In: ALL-PARTY OIREACHTAS COMMITTEE ON THE CONSTITUTION. Second Progress Report Seanad Éireann. Dublin: Stationery Office, p. 32-107, 1997. Disponível em: <https:/goo.gl/bh6rNh>. Acesso em: 14 abr. 2017.

DARDANELLI, Paolo. The parliamentary and executive elections in Switzerland, 2003. Electoral Studies, v. 24, n. 1, p. 123-129, 2005.

DREXHAGE, Betty. Bicameral Legislatures An International Comparison. The Hague: Ministry of the Interior and Kingdom Relations, 2015.

ESTADOS UNIDOS. Constitution of 1787 (Atualizada em 1992). Disponível em: <https://goo.gl/it7lcG>. Acesso em: 15 mar. 2017.

ETIÓPIA. Constitution of 1995. Disponível em: <https://goo.gl/Fjr3Lb>. Acesso em: 15 mar. 2017.

GAVRIC, Saša; BANOVIC, Damir; BARREIRO, Mariña. The Political System of Bosnia and Herzegovina. Institutions - Actors - Processes. Serajevo: Edition BH politika/BH politics, 2013. Disponível em: <https://goo.gl/Y9wB7u>. Acesso em: 15 abr. 2017.

HAMMOND, Basil E. Bodies Politic and their Governments. Cambridge: The University Press, 1915.

HAYS, Dan. Reviving Conference Committees. Canadian Parliamentary Review, p. 8-10, 2008.

HRBEK, Rudolf. Germany Federal Republic of Germany. In: GRIFFITHS, Ann L.; NERENBERG, Karl (Ed.). Handbook of Federal Countries, 2002. Montreal/London/Ithaca: McGill-Queen's University Press, 2002, p. 148-160, 2002. 
HUEGLIN; Thomas O.; FENNA, Alan. Comparative Federalism: A Systematic Inquiry. Toronto: University of Toronto Press, 2015.

ÍNDIA. Constitution of 1950 (Atualizada em 11/2015). Disponível em: <https://goo.gl/DVs9i>. Acesso em: 15 mar. 2017.

LEHNERT, Matthias; LINHART, Eric; SHIKANO, Susumu. Never say never again: legislative failure in German bicameralism. German Politics, v. 17, n. 3, p. 367-380, 2008.

LIJPHART, Arend. Patterns of Democracy: Government Forms and Performance in Thirty-Six Countries. New Haven: Yale University Press, 1999.

LONGLEY, Lawrence D.; OLESZEK, Walter J. Bicameral Politics: Conference Committee in Congress. New Haven: Yale University Press, 1989.

MCQUILLAN, Lawrence J.; ORTEGA, Lydia D. Conference Committee Participation and Party Loyalty. Public Choice, v. 74, n. 4, p. 485-494, 1992.

MÉXICO. Constitución de 1917 (Atualizada em 24/02/2017). Disponível em: $<$ https://goo.gl/ChOJ9>. Acesso em: 15 mar. 2017.

NEIVA, Pedro Robson P.; SOARES, Márcia M. Senado brasileiro: Casa Federativa ou Partidária? Revista Brasileira de Ciências Sociais, v. 28, n. 81, p. 98-115, 2013.

PAQUISTÃO. Constitution of 1973 (Atualizada em 7/1/2015. Disponível em: <https://goo.gl/PKwz1>. Acesso em: 15 mar. 2017.

PATTERSON, Samuel C.; MUGHAN, Anthony. Fundamentals of Institutional Design: The Function and Powers of Parlamentary Second Chambers. In: BALDWIN, Nicholas; SHELL, Donald (Ed.). Second Chambers. London/Portland: Frank Cass, p. 39-60, 2001.

PULIDO, Oscar Manuel R. La Enrevesada Destitución del Presidente de la República en México. Derecho en Acción, 17/01/2017. Disponível em: <https:/goo.gl/1MH71u>. Acesso em: 14 abr. 2017.

RIKER, William H. The Justification of Bicameralism. International Political Science Review, v. 13, n. 1, p. 101-116, 1992.

ROGERS, James R. An Informational Rationale for Congruent Bicameralism. Journal of Theoretical Politics, v. 13, n. 2, p. 123-152, 2001.

RUSSELL, Meg. Reforming the House of Lords - Lessons from Overseas. Oxford: Oxford University Press, 2000.

RÚSSIA. Constitution of 1993 (com emendas até 2008). Disponível em: <https://goo.gl/Fpbtmf>. Acesso em: 15 mar. 2017.

SAMPAIO, José Adércio L; PINTO, João Batista M. O Federalismo Ambiental na Austrália e na Índia. Veredas do Direito, v. 12, n. 23, p. 67-89, 2015. 
SAMPAIO, José Adércio Leite. A Constituição Reinventada pela Jurisdição Constitucional. Belo Horizonte: Del Rey, 2002.

SCHUBERT, Louis; DYE, Thomas R.; ZEIGLER, Harmon. The irony of democracy: An uncommon introduction to American politics. 15. ed. Boston: Wadsworth, 2012.

SHARMA, Brij K. Introduction to the Constitution of India. 7. ed. New Dheli: PHI Learning, 2015.

SHEPSLE, Kenneth A.; WEINGAST, Barry R. The Institutional Foundations of Committee Power. American Political Science Review, v. 81, n. 01, p. 85-104, 1987.

SINGHVI, L. M. The Legislative Process in India. Journal of Constitutional and Parliamentary Studies, v. 4, p. 1-32, 1970.

SUDÃO DO SUL. Constituição de 2011. Disponível em: <https://goo.gl/tHR7RV> Acesso em: 11 abr. 2017.

SUDÃO. Constitution of 2005. Disponível em: <https://goo.gl/JcBRN3>. Acesso em: 15 mar. 2017

SUIÇA. Constituição de 1999 com emendas até 2016. Disponível em: <https://goo.gl/JcBRN3>. Acesso em: 11 mar. 2017.

SWEDEN, Wilfried. Federalism and Second Chambers: Regional Representation in Parliamentary Federations: The Australian Senate and German Bundesrat Compared. Bruxelles: Lang, 2004.

SWIFT, Elaine K. The Making of an American Senate: Reconstitutive Change in Congress, 17871841. Ann Arbor: University of Michigan Press, 2002.

TSEBELIS, George; MONEY, Jeannette. Bicameralism. Cambridge: Cambridge University Press, 1997.

VERDUSSEN, Marc. La Dernière Réforme du Sénat de Belgique. Revista Catalana de Dret Públic, n. 51, p. 74-84, 2015.

VICENTE, Paulo César. Prevalência da Câmara dos Deputados no processo legislativo bicameral: a Lei de improbidade administrativa. Brasília: Centro de Formação, Treinamento e Aperfeiçoamento da Câmara dos Deputados/CEFOR, 2012. Disponível em: <https://goo.gl/95fqjh>. Acesso em: 11 abr. 2017.

WÄLTI, Sonja. Balance and imbalance in the Swiss federal system. In: COMMISSION ON FISCAL IMBALANCE. Texts Submitted for the International Symposium on Fiscal Imbalance. Québec: CDF, 2001, p. 101-111.

WATTS, Ronald L. Comparing Federal Political Systems. In: GAGNON, Alain-G.; KEIL, Soeren; MUELLER, Sean (Ed.). Understanding Federalism and Federation. London: Routledge, 2015, p. 11-30.

WATTS, Ronald L. Comparing Federal Systems in the 1990s. Montreal: Queen’s University 
Kingston, 1996. Disponível em: <https:/goo.gl/cWUN6N>. Acesso em: 11 mar. 2017.

WHITTLE, Patricia. The power to negotiate: examining mandating procedures in the National Council of Provinces and their impact on legislation and other parliamentary processes. 2016. (Dissertação). University of Cape Town, 2016. Disponível em: <https://goo.gl/821jqZ>. Acesso em: 11 maio 2017.

WOOD, Gordon. The Creation of the American Republic, 1776-1787. New York: Norton, 1969.

José Adércio Leite Sampaio Doutor e Mestre em Direito pela Universidade Federal de Minas Gerais. Professor na Pontifícia Universidade Católica de Minas Gerais e na Escola Superior Dom Helder Câmara. Procurador da República. E-mail: joseadercio.contato@gmail.com 